\title{
Tracing the sources of organic matter in the Seine Estuary (NW France) using bulk and molecular analyses
}

\author{
A. HUGUET $^{1 *}$, A. THIBAULT ${ }^{1}$, C. ANQUETIL ${ }^{1}$, \\ S. DERENNE ${ }^{1}$
}

${ }^{1}$ UMR METIS, Sorbonne Université/CNRS/EPHE, Paris, France (*correspondence : arnaud.huguet@sorbonneuniversite.fr)

Estuaries are key ecosystems from economical and ecological points of view. This is especially true for the Seine Estuary, its watershed representing $12 \%$ of the France area, in which $30 \%$ of the French population, $40 \%$ of the industry and $25 \%$ of the agriculture are concentrated. Estuaries transfer material from the continent to the oceans, including organic matter $(\mathrm{OM})$, for which they are highly reactive zones. Elucidating the estuarine OM dynamics remains challenging, due to (i) the high variability of environmental parameters, (ii) the intrinsic heterogeneity and molecular diversity of $\mathrm{OM}$ and (iii) the permanently changing nature of this material.

The aim of this work was to better constrain the sources of $\mathrm{OM}$ in the Seine Estuary. In order to take into account the spatiotemporal variability of OM characteristics, water and sediment were collected all along the estuary during 5 campaigns with different tidal intensities and river flows. Elemental $(\mathrm{C}, \mathrm{N})$ and isotopic composition $\left(\delta^{13} \mathrm{C}\right.$ and $\left.\delta^{15} \mathrm{~N}\right)$ as well as lipid biomarkers were analyzed in both particulate (POM) and sediment OM. This allows comparing the bulk and molecular composition as well as sources of OM in the particulate and sediment pools.

Several lipid biomarkers ( $n$-alkanes, fatty acids, nalcohols, sterols/stanols, GDGTs) were investigated in this study, as they provide complementary information of the sources and degradation degree of OM. Lipids from terrigenous sources were predominant in all samples, even though the concentrations of these compounds as well as those of anthropogenic origin were shown to decrease towards the mouth of the Seine Estuary. In addition, significant differences in bulk and molecular composition were observed between the particulate and sediment pool, especially with a higher abundance of aquatic (i.e. algal/bacterial) vs. terrigenous lipids in POM than sediment OM. Last, bulk and molecular analyses both showed the strong seasonal and spatial variability (along the estuary and with depth) of OM composition in the water column and sediment, which has to be taken into account when investigating estuarine OM dynamics. 